\title{
Differences between the SCALE-UP model and instructors' perceptions of implementation
}

\author{
Brian Zamarripa Roman ${ }^{1}$, Constance M. Doty ${ }^{1}$, Matthew Wilcox ${ }^{1}$, Noel Klinger ${ }^{2}$, Jarrad W. T. Pond ${ }^{3}$, Joshua S. Von Korff ${ }^{4}$ \\ and Jacquelyn J. Chini ${ }^{1}$ \\ ${ }^{1}$ Department of Physics, University of Central Florida, 4111 Libra Drive, Orlando, FL, 32816 \\ ${ }^{2}$ Department of Physics, George Washington University, $72521^{\text {st }}$ Street NW, Washington, DC, 20052 \\ ${ }^{3}$ Department of Physics and Astronomy, University of Georgia, 1510 Cedar Street, Athens, GA 30602 \\ ${ }^{4}$ Department of Physics and Astronomy, Georgia State University, 25 Park Place, Atlanta, GA 30303
}

Recent research has highlighted the need to explore the propagation of innovative teaching strategies. SCALE-UP (StudentCentered Active Learning Environment with Upside-Down Pedagogies) is one such innovative strategy that requires transforming the learning space to support small group work. SCALE-UP is both well-propagated and frequently sustained within departments once it is implemented, possibly due to the investment in a transformed learning space. However, not all instructors and departments reach the significant learning gains typically documented in the literature. In this study, we use interviews to explore the extent to which individual instructors implement and sustain specific features of SCALE-UP, like reduced lecture time and group composition, because such features may be more easily modified over time than the classroom space. We report on instructors' perceptions of the extent to which their courses align with the SCALE-UP model and whether deviations from the literature-based model result from intentional or unintentional changes.

\section{INTRODUCTION}

Recent calls to action have emphasized the need for student-centered pedagogies [1], as such practices have been tied to significant learning gains [2]. SCALE-UP is one such pedagogy, which has been well propagated since it was developed in the 1990s as an alternative to traditional lecture and laboratory courses [3].

SCALE-UP promotes learning by centering classroom time around student interaction as opposed to a traditional lecture, which is centered on the instructor. This style of class integrates lecture and laboratory components into one classroom setting that takes place 4-6 hours per week. To promote student-centered learning, the model requires a specialized classroom with large tables, computers at every table, whiteboards, and lab equipment. Instructors are often supported by classroom assistants such as Graduate Teaching Assistants (GTAs) and Learning Assistants (LAs). In addition to physical space requirements, SCALE-UP instructors need to plan for student engagement by emphasizing and facilitating student group interactions, realworld problem solving, conceptual understanding, and providing activities such as labs, tangibles, and ponderables [3]. To make time for this in class, students are expected to gain knowledge outside of class. These aspects of SCALEUP are essential to its design and successful implementation.

Due to the freedom of SCALE-UP's student-centered approach, it is documented that different instructors have wide variation in how class time is spent [4]. In fact, learning gains appear to depend more on the instructor's pedagogy than the classroom environment [5], and the potential learning gains have not been achieved when student-centered pedagogies are left out of technology-rich environments [6].
In the present study, we explore the reasons that instructors modify pedagogical aspects of SCALE-UP that they have immediate control over, such as activities, duration of lecture, group making, group training, groups roles, and their utilization of GTAs/LAs. Our guiding research question is: what are the differences between the SCALE-UP model and instructors' perceptions of their own implementation, and what has led them to those differences? We will explore the tension between instructors' perceptions of the SCALEUP model and what instructors believe is best for their students' learning given their own experiences leading SCALE-UP courses.

\section{METHODOLOGY}

\section{A. Participants and data collection}

We interviewed SCALE-UP physics instructors from two large doctoral granting universities on the east coast. At University A, we interviewed five tenured or tenure track and three non-tenure track faculty. These instructors had experience teaching SCALE-UP ranging from two semesters to more than ten semesters, most with at least five semesters of experience. At University B, we interviewed two tenured faculty and three adjunct professors. Most instructors at University B had at least four semesters of experience, but one instructor had no prior experience with SCALE-UP. Pseudonyms have been assigned to the instructors to protect their identity, with the first letter indicating institution.

The interviews were semi-structured, allowing for follow-up questions and elaboration from the instructors. Interviews took place shortly after an observation of the instructor's class, so questions may be asked or answered with context from the observed class. Several questions in 
the interview protocol probe the instructor's approach to teaching the class, how they learned about teaching SCALEUP, what changes they made to how they teach classes, and the roles of students in class.

\section{B. Data analysis}

Two researchers identified themes within interviews for the present study. Initially, each researcher focused on a single institution, coding the dialogue according to an aspect of SCALE-UP and looking for the reason the instructor changed that aspect. The analysis focused on principles of SCALE-UP that can be implemented or changed directly by the instructor. We compared instructor perception of their implementation to the literature-based SCALE-UP model or their perception of the SCALE-UP model based on the context of the instructors' responses. For example, if the instructor mentioned he knows he spends too much time lecturing and says it is because the students are not reading, the dialogue would be coded as increased lecture time, and the change would be coded as a result of the lack of student preparation. Such a statement also indicates the instructor perceives the SCALE-UP model uses reduced lecture time.

To ensure reliability of the interview analysis, the researchers read at least two interviews from the other institution. After discussion, a consensus was reached on the themes presented here.

\section{RESULTS}

Our analysis revealed similar themes centered on lecture time, group composition, the types of activities that are conducted in class, and GTA/LA roles at both institutions. We report the extent to which each theme was repeated and support the claims with quotes to highlight the differences.

\section{A. Lecture time}

A key principle in SCALE-UP is that students are expected to acquire knowledge before class, and engage in flipped pedagogies during class to apply the knowledge. This allows for class time to be spent clarifying and wrestling with concepts through hands-on activities, problem solving and questions. Lectures are recommended to last 10-15 minutes daily, for the purpose of motivation and summary [3].

\section{Increased lecture time}

A major result of our analysis is the instructors' perceptions of spending too much time reviewing content intended to be learned outside of class. A recurring reason for this difference is that instructors perceive most of their students do not read or engage meaningfully in out-of-class assignments. Adrian explained his reasoning:

Adrian: ...even though they are supposed to read, they don't actually all of them read anything. So, um, some of them read but some of them also don't come prepared and don't read, and so I like to give a, at least some summary, brief summary of what's the concept we're going to work with...

This theme of perceiving that students do not read outside of class was reported in ten interviews. Most instructors responded by adding extra lecture slides or adding a review at the beginning of class. It is worth noting that one of the instructors had a different approach to extended lecture:

Alex: ...they really didn't read [before class] and the one thing, even though I do a little bit of lecturing, I usually try to match it with the [clicker questions] piece so that it's not really just a pure lecture...

By implementing other aspects of SCALE-UP during the lecture, Alex, tried to maintain the central active learning theme of the model.

\section{Decreased lecture time}

Only one instructor perceived himself as having too little lecture because he placed a lot of stock in students learning from the book outside of class.

Bobby: ... when I started uh the first time, I remember talking to [developer] and telling him how I might have out of 30 slides, 2 slides with lecture material. ...he sort of reacted and said, "Whoa, I present like 10, I have more than that." So I guess I felt maybe I'd gone overboard... I mean I really bought into the notion that the book has this material that... is professionally prepared and presented and can be looked over and over and over again, and I don't want to be rehashing that and representing or retransmitting that when the students can really be responsible for that.

Even though this was not a recurring theme, it is worth noting that Bobby's minimized lecture was surprising to a SCALEUP developer because increased lecture is typical.

\section{B. Groups}

The creation and function of student groups is a central aspect of the SCALE-UP model as it allows for students to explain acquired knowledge to their peers and collaborate to deepen understanding. The SCALE-UP literature provides recommendations for how to create, train, and change groups throughout the semester [3]. Three themes of differences arose from the data: instructors modify guidelines for group making, student training on group roles is not emphasized, and groups are changed less frequently than recommended.

\section{Group making}

Many of the instructors were aware of the recommended process to create groups: each group should have a student from the top, middle and bottom of the class based on assessments and should not have any isolated minorities [3]. However, many instructors commented that they chose other criteria to follow based on personal beliefs. This occurred in 
nine interviews, with Angel's response exhibiting many of the criteria used by other instructors:

Angel: ...first day of class what I do is that I, I spend time looking at their, you know, all the registration information that I can get about them, like their majors, ...gender, interests, ...how senior they are... Um, I run a little survey on the first day where I ask them about how many physics class they have taken in their lives, how many calculus classes or math classes they have taken, if they... done well in their physics and math classes... I try to group them in a way that I mix gender, I mix uh, you know minorities and majorities and, you know, everything.

Angel grouped students similarly to the model, but added additional criteria to determine student standing. Other instructors used similar methods, even including their perceptions of student personalities.

Two instructors highly regarded students' requests to form their own personal groups. They had similar beliefs that students would be more receptive to working with people of their own choosing, a dynamic that would facilitate group work, as expressed by Benny:

Benny: Well the first thing that happened then was they, Chinese students, come and petition me to be put into groups with other Chinese students because, "there is my language difficulty and I can communicate better with my confreres". So next time we shuffle the tables, I put all the Chinese students in with other Chinese students.

Benny grouped Chinese students to facilitate communication with their peers. Like Benny, another instructor described her willingness to create groups to meet students' individual desires, such as women who do or do not want to be in groups with other women.

\section{Group training}

Once groups are assigned, the instructor should teach students how to interact to promote cooperative learning. Part of that training, in the SCALE-UP model, is to introduce the group roles of the manager, skeptic and recorder [3]. No instructors reported using these roles. Seven instructors explicitly stated they did not use them, like Benny:

Int: Um do you do anything to train the students about how to work together in the groups?

Benny: ...I know there are these three roles, the scribe, the skeptic and the manager, but they all seem to float so freely from one role to another that I haven't really tried to pin that down.

In this excerpt we see how Benny chose not to control the roles because students would not stick to the assigned roles.

\section{Changing groups}

Even though instructors tend to change the groups, twelve do not change them as frequently as suggested (three to four times per semester, typically after exams) [3]. The instructors reported changing groups once or twice per semester, or not at all. Bart shared an example of this:

Int: Do you change those groups during the semester?

Bart: Once or twice, yes. This semester I only did it once... Mostly because the second midterm was just like a week ago and it seemed like for the remaining three weeks to change their groups was kind of silly, so I didn't.

Bart described that he did not change groups because the triggering event of the exam was deep into the semester.

\section{Activities}

SCALE-UP does not prescribe a specific curriculum to implement. However, the activities should be designed to emphasize conceptual understanding, including hands-on activities and estimation. Most instructors reported modifying activities that were passed on to them. This is a result of different personal beliefs of how and what content should be covered in class. For example, Adrian explained:

Adrian: ... the first semester I did it exactly the same way as [previous instructor] was doing ... But then there is some things that ... didn't feel naturally for me to talk about it that way, or I could tell that the students were struggling ...

Even within the same section, different instructors will have different activities. This modification of material occurs even when obtained from a viable source, as demonstrated by Bobby:

Bobby: ...when we started SCALE-UP... I talked to [developer] about getting his materials, and he burned me a CD with all of his stuff, ... and I opened the CD, and I couldn't make heads or tails of what was there... And then we had just started and I got the book, the [current] book and I looked at the workbook and I said, "This is a great conceptual problem ... ", and then I realized there's a whole series of great conceptual problems ... So, I just went that way, and I sort of threw the CD away.

In this example, we see even though Bobby received content directly from a developer of SCALE-UP, misunderstandings and misalignment were some of the reasons for modifying the activities as provided.

\section{GTAs/LAs}

Classroom assistants such as GTAs and LAs are essential in bridging the gap of knowledge between instructors and students. Their assistance often involves circulating the room, engaging in dialogue with the students during classroom activities, grading assignments, and reporting student feedback to the instructor. Therefore, weekly meetings between the instructor and assistants are recommended and provide an opportunity for the instructor to both guide the pedagogical experience the assistants will create and gather feedback from the assistants to improve the course overall [3]. Only six instructors mentioned hosting 
such meetings. The rest mentioned schedule conflicts as the main barrier to the meetings. Bernie is required to have weekly meetings by the LA program and offered his opinion:

Int: Do you, so if your LA coordinator is running a tight ship, are you required to have like a weekly meeting with the LAs?

Bernie: Yes

Int: Okay, and does that, do you find that helpful? Would you do that if you weren't required to do that?

Bernie: Um, I probably wouldn't, but I do find it really helpful, and I'm pretty strict about it, it's in the contract. I mean it's just, LAs come, in the beginning of the semester they have a contract that I sign, that's one of the elements in the contract.

Even though Bernie acknowledges the utility of GTAs/LAs, he still claims he would not hold meetings if not required to.

\section{CONCLUSION \& DISCUSSION}

While analyzing the interviews, major trends emerged including extended lecture time, differences with group dynamics, variations of activities performed during class, and lack of meetings with GTAs/ LAs. These themes all fit under the umbrella of pedagogical aspects controlled by the instructors. Many of these changes, such as increasing lecture time and changing group formation guidelines, appear to be responsive to the needs or desires of the instructor's individual class. Thus, we find the instructors in a place of tension, forced to choose between implementing SCALE-UP as suggested in the literature or responding to their own teaching environment.

Most instructors responded to their perception of students not completing pre-class readings by extending their lectures so that students may acquire the knowledge needed to complete in-class activities. Although extended lecture is not recommended by the SCALE-UP model, it may be possible to effectively use that time by implementing other principles of the model, such as interactive assessments. This was done by Alex when he integrated the clicker questions so that he did not have a "pure" lecture. Instructors' perceptions may also be student resistance, which prior studies reveal is a major barrier to transforming instruction [7]. Further work is needed to explore the extent to which such variations maintain the large learning gains associated with the original SCALE-UP model and characterize students' engagement outside of class.
Group making and training had similar differences in that instructors would be lenient in enforcing model principles by being responsive to students. Group make-up was at times left for students to decide, since instructors believed students know what works best for them. Frequently, group roles were not emphasized because instructors did not see students following the roles. This may be another example of student resistance to student-centered pedagogies. Instructors tended to respond by ceding the responsibility of group dynamics to the students rather than focusing more attention and training on following the guidelines for group formation and roles.

Differences in content and activity coverage across similar classes are consistently found in the literature. This has been attributed to instructors' preferred beliefs of what content should be covered to effectively develop conceptual understanding. Misunderstandings when transferring content from one instructor to the next also lead to differences in activities [8]. Such challenges were evident when Bobby went a different route with activities because he was unable to make sense of the CD provided. SCALE-UP classrooms are not meant to be exact copies of a model, however, variations can be minimized by sharing content in clear and concise manners.

Even though scheduling was the main conflict for holding GTA/LA meetings, instructors said the meetings were useful. Bernie held weekly meetings and found them useful, yet said he would not hold them if they were not required. Successful meetings are not enough motivation for instructors to hold them, and future work should explore why some instructors implement meetings while others do not.

Our results are limited to the two universities studied. Examining a wider set of institutions will deepen our understanding of instructor perceptions of their SCALE-UP implementations. To encourage this, it would be beneficial to include both universities with only SCALE-UP classes and a mixture of SCALE-UP and lecture classes, smaller universities and departments other than Physics. Future work should also address methods to support instructors in fully implementing essential features of the SCALE-UP model.

\section{ACKNOWLEDGEMENTS}

This work was supported by the National Science Foundation Grant Nos. DUE 1347510, 1347515 and 1347527.
[1] Vision and Change: A Call to Action (American Association for the Advancement of Science, Washington, DC, 2009).

[2] R. R. Hake, Am. J. of Phys. 66, 64 (1998).

[3] R. J. Beichner, et al., Research-Based Reform of University Physics (American Association of Physics Teachers, College Park, MD, 2007).

[4] M. Wilcox, et al., in Physics Education Research Conference Proceedings, (2016), pp. 392-395.
[5] P. A. G. Soneral and S. A. Wyse, CBE Life Sci. Educ. 16, ar12 (2017).

[6] N. Lasry, et al., in AIP Conference Proceedings, (2013), pp. 238-241.

[7] C. Henderson and M. H. Dancy, Phys. Rev. ST Phys. Educ. Res. 3, 020102 (2007).

[8] K. T. Foote, Phys. Rev. Phys. Educ. Res. 12, 10127 (2016). 